\title{
Interactive Community Simulation Environment for Community Health Nursing
}

\author{
Michelle Hogan \\ Faculty of Health Sciences, \\ University of Ontario Institute of Technology. \\ Oshawa, Ontario, Canada. L1H 7K4. \\ michelle.hogan@uoit.ca
}

\author{
Hamed Sabri and Bill Kapralos \\ Faculty of Business and Information Technology, \\ University of Ontario Institute of Technology. \\ Oshawa, Ontario, Canada. L1H 7K4. \\ bill.kapralos@uoit.ca
}

\begin{abstract}
The majority of nursing curriculums continue to relate experiences and examples of nursing to the more familiar role of "nurse clinician". Specifically, the use of simulation and technology has been used in the undergraduate nursing program to assist learners in developing nursing skills and knowledge for treating individual patients with acute and chronic conditions. Nursing students are now able to apply learned concepts of nurse clinician when treating virtual patients and while engaging in simulation-based education. The use of such simulation in undergraduate nursing education allows learners to readily apply skills and knowledge within a safe learning environment; however, the use of such technology has not been widely adopted to address the learning needs of today's community health nursing students. In fact, despite its importance, the role and process of community health nursing is often unknown to many undergraduate nursing students. This paper presents a strategy-based, interactive community simulation environment that addresses the learning needs of millennial students within a community health nursing curriculum.
\end{abstract}

\section{Categories and Subject Descriptors}

I.3.8 [Computer Graphics]: Three-Dimensional Graphics and Realism-Applications

\section{General Terms}

Human Factors

\section{Keywords}

Community health nursing, serious games, interactive learning environment, game-based learning.

\section{INTRODUCTION}

The role of community health nursing can be traced back to the origin of nursing practice. The ever changing needs of our communities, emerging social and health issues, and

Permission to make digital/hard copy of part of this work for personal or classroom use is granted without fee provided that the copies are not made or distributed for profit or commercial advantage, the copyright notice, the title of the publication, and its date of appear, and notice is given that copying is by permission of the ACM, Inc. To copy otherwise, to republish, to post on servers, or to redistribute to lists, requires prior specific permission and/or a fee.

FuturePlay 2007, November 15-17, 2007, Toronto, Canada

Copyright 2007 ACM 978-1-59593-943-2/07/0011_..\$5.00 current and future demands on our health care system have created a much needed shift in health care delivery from that of hospital to community. Currently, approximately $70 \%$ of nurses work in hospitals as nurse clinicians [9]. By 2020, it is estimated that $75 \%$ of nurses will work in and with the community, thus creating a greater need for qualified, competent community health nurses [9].

Unlike a nurse clinician, the role and practice of community health nursing is very different. Whereas nurse clinicians are concerned with caring for the health of individuals, community health nurses are concerned with caring for, and promoting the health of entire communities. Their target of practice, the strategies they use, and the desired outcomes are all very different and therefore, require different skills, training, and education. Community health nurses must be competent in critical thinking abilities and core public health sciences, the foundational knowledge necessary to practice effectively [4]. Application of these basic public health sciences involves the use of techniques such as surveillance, monitoring, analysis, investigation, health promotion, capacity building, healthy public policy, research, development, evaluation, and innovation [4]. They must also be competent in assessment and analysis, the ability to collect, assess, analyze and apply health information in improving the health of their communities [4]. This competency provides the foundation to establish evidence-based priorities, make decisions, budget, develop policy and plan programs [4]. Community health nurses must be proficient in policy development and program planning, including the ability to identify, assess and choose appropriate policy options, and to plan, implement, monitor, and evaluate policy [4]. When working with the community as a patient, community health nurses must also be competent in their ability to work with others. Partnership and collaboration are the cornerstones of community health nursing and will optimize performance through shared resources and responsibilities [4]. Community health nurses should be competent in communication, including: internal, external, written, verbal, non-verbal, listening skills, providing information appropriate to different audiences, use of media and social marketing techniques [4]. Community health nurses are required to interact effectively with a diversity of individuals, groups and communities and demonstrate effective leadership skills [4]. Unlike the skills required for that of a nurse clinician, much of these skills and their application cannot be carried out within newly developed and highly innovative practice lab facilities where the focus of patient care is the individual. Therefore, developing 
innovative ways to teach the approach and process of community health nursing is very challenging. For this reason, community health nursing curriculums have predominantly relied on traditional teaching-and-learning approaches where the application and practice of such skills is often quite difficult.

\subsection{The Millennial Student}

Traditional teaching-and-learning environments are often quoted by millennial students (the generation raised in the sensory-flooded environment of digital technology and mass media e.g., the "internet generation", or as designated by Prensky [7], the digital natives) as "boring" and do not address the unique learning needs of this generation. Millennials are very technologically literate and see technology as a necessity, both in life and in learning [3]. The fact that the millennial generation has always been digitally connected has led to a mindset unlike any that nursing faculty have ever seen. Understanding this mindset is an important aspect of educational planning and course development. Specifically, according to Villeneuve [14], this generation does not remember a time without e-mail, internet, cell-phones or lap-top computers. This lived experience and their unique way of being and knowing has largely influenced the learning needs of this generation of nursing students. It is not surprising that this generation highly regards "doing rather than knowing", making interactive, experiential learning a necessity for their educational success. This generation prefers, expects and appreciates the use of technology in learning. In order for knowledge and skills to become fully understood, integrated and accessible for future situations, millennial students require reinforcement, application, repetition, and often practice in a variety of settings and contexts [8]. Virtual environments and video games offer that opportunity, whereby students can practice their skills and abilities within a safe learning environment, leading to a higher level of self-efficacy when faced with real life situations where such skills and knowledge are required [2].

\subsection{Serious Games}

In contrast to traditional teaching and learning environments whereby the teacher controls the learning (e.g. teacher centered), video games present a learner centered approach to learning whereby the player controls the learning through interactivity and allows the player to learn via active, critical learning [10]. Video games provide students the opportunity to learn to appreciate the inter-relationship of complex behaviors, sign systems, and the formation of social groups [1]. In addition to these benefits, the advantages of video games to other applications have not gone unnoticed In fact, video game technology has been adopted and applied to applications whose primary purpose is not entertainment. These are referred to as serious games. Although no particularly clear definition of the term is currently available, serious games usually refer to games that are used for training, advertising, simulation, or education and are designed to run on personal computers or video game consoles [12] (serious games have also been more loosely defined as "games that do not have entertainment, enjoyment, or fun as their primary purpose [5]). Serious games "leverage the power of computer games to captivate and engage players for a specific purpose such as to develop new knowledge or skills". Specifically, serious games support the development of ana- lytical and spatial, strategic, recollection, and psychomotor as well as visual selective attention skills [6]. Further benefits of serious games include improved self-monitoring, problem recognition and solving, improved short- and long-term memory, increased social skills, and increased self-efficacy $[6,13]$.

Serious games have been employed in a number of learningbased applications including educational, national, security, corporate management, military, government, and in the training of emergency personnel/first responders and healthcare workers. The application of serious games can be broadly categorized into four categorize: i) military, ii) government, iii) education, and iv) corporate. Recently, there has been a great effort in the development of applications related to health and healthcare. The number of potential applications within the healthcare category is large and includes, amongst others, physical fitness, education in health/self-directed care, recovery and rehabilitation, and diagnosis and treatment of mental illness/mental conditions $[12]$.

\subsection{Goal of this Work}

Despite the relevance and importance to millennial students, the use of technology has not been widely adopted to address the learning needs of today's community health nursing students. The use of simulation and technology has been widely applied in nursing curriculums to address the skills and competency of nurse clinicians while little to no innovative technology has been developed to address the skills and competency of community health nurses. Specifically, the use of simulation and technology is frequently used in the undergraduate nursing program to assist learners in developing nursing skills and knowledge for treating individual patients with acute and chronic conditions. The use of such simulation allows learners to readily apply skills and knowledge within a safe learning environment, an opportunity not formerly available to community health nursing students. This current project will address this large gap in community health nursing curriculums while simultaneously addressing the educational needs of millennial students through the use of video game-based technology. Research on education has consistently found that the use of video games for educational purposes helps increase variables like skill and feelings of self-efficacy [13].

This paper presents a strategy based, interactive community simulation environment whereby a learner centered approach to learning is taken, engaging students while allowing them to control their own learning through interactivity. Students are able to engage in discovery learning where the instructor is no longer the primary source of information but a facilitator of their learning. This strategy based, interactive simulation environment allows students to explore and practice repeatedly, the role of community health nursing within a safe learning environment. Students move through the nursing process; conducting a nursing assessment of a virtual community, determining community diagnoses and implementing strategies within the virtual community to address the identified health issues.

The goals of this cognitive development are to assist students to: 
- Engage in the community health nursing process- assessment, diagnosis, analysis, planning, intervention, and evaluation.

- Develop critical and reflective thinking skills.

- Explore models of community health nursing practice.

- Reinforce key learning concepts.

- Enhance competency and feelings of self-efficacy

\section{SIMULATION OVERVIEW}

The strategy-based, interactive, simulation environment supports various learning modules. The initial module focuses on the application of the nursing process with community-as-patient. The simulation begins with an overview of the community (see Figure 1(a)). The view of this community gives the student information pertaining to: location (geographic boundaries, climate, plants, and percentage of urban and rural life), housing (type, condition, slum areas, sanitation, adequacy, crowding, etc.), water supply, and sanitation (sewage and waste disposal). The student can choose to investigate a specific part of the community further (see Figure 1(b)).

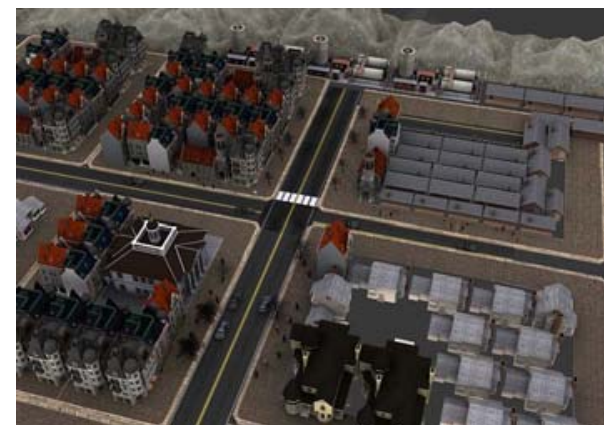

(a) Community overview.

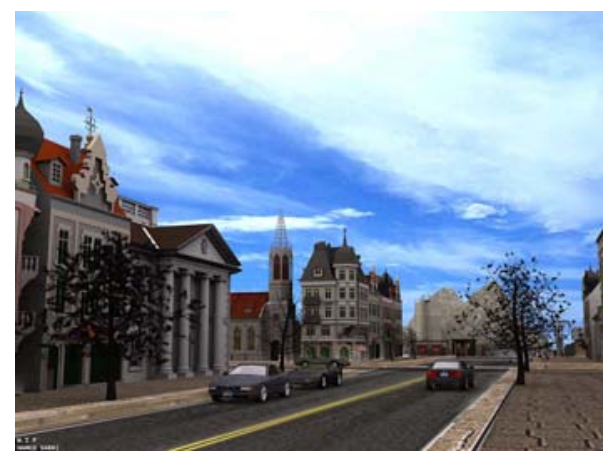

(b) Focusing on one part of the community.

Figure 1: Community View.

The student is then able to navigate through the community and interact with characters and objects he/she may encounter. Interactions include choosing any of the objects (e.g., school, churches, police stations and other institutes), or characters (e.g., people such as police officers, homeless, etc.) within the community overview. This interaction provides the students with information specific to the

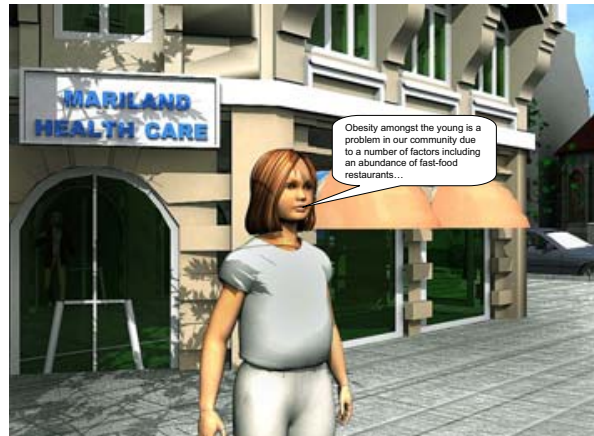

(a) Interacting with an obese child.

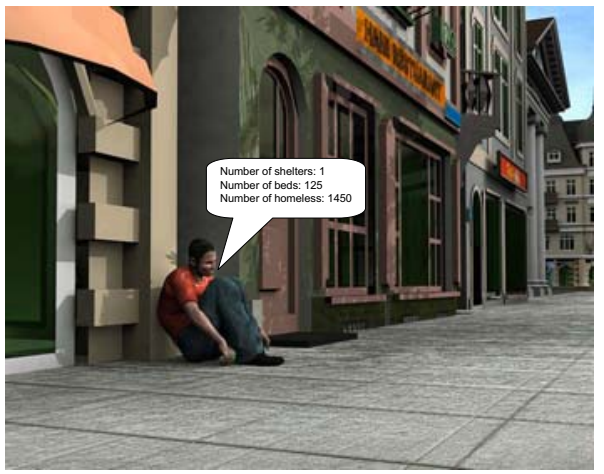

(b)Interacting with a homeless person.

Figure 2: Interacting with the community.

object/character they are interacting with. For example, by choosing to interact with a homeless person, information pertaining to the homeless (e.g., location of homeless shelters, estimated number of homeless in the community, etc.) is presented to the student. Information is presented in either a "caption bubble", within the user interface, or through audio. Two examples are illustrated in Figure 2. In Figure 2(a), the student has encountered an obese child and chooses to interact with them. This provides the user with information regarding obesity and diet with respect to the community. In Figure 2(b), the student has encountered a homeless character and chooses to interact with them. As a final example, in Figure 3, the student has entered the public health building where he/she encounters a public health nurse who provides information regarding public health services offered in the community.

The student continues navigating through the environment while gathering information as they do so. As part of the total experience, the student is able to retrieve and examine resources within a virtual book repository to assist them in their assessment. Once the student feels they have completed a thorough assessment of the community, the student can then analyze the data and input a "community health diagnosis". As several community health issues/problems exist, students will have to determine which problem they feel is a priority given their assessment and analysis. However, the path they follow in the simulation is determined by the health issue/problem they choose. 


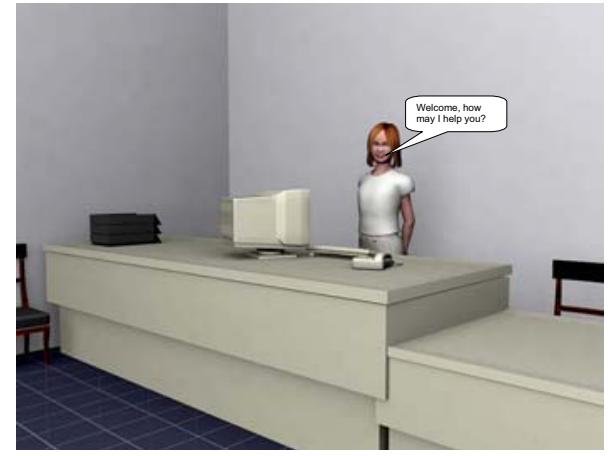

Figure 3: Interacting with a public health nurse.

Following the identification of a community health issue, students must then identify various strategies that could be used to address the health issue/problem. Students must identify resources required to implement such strategies before the actual implementation takes place. The implementation of these strategies alters the health of the community and is directly observable within the virtual community. This provides an opportunity for students to reflect on and evaluate the impact of his/her role and the strategies chosen and to develop higher order thinking skills. Following the completion of the nursing process, a report is produced to examine the thoroughness of the student's assessment, areas missed, other possible diagnoses and interventions. This report provides the means for educators to evaluate a student's success and allows the educator to provide the student feedback. Students are able to re-enter the community as often as necessary to practice skills, identify different health problems/issues and implement different strategies to address the issues. Students have control over the information gathered, strategies implemented and the frequency of which they revisit the community. According to Stout, et al. [11], learner control is an important element for successful learning experiences because it can have a positive impact on students' performance, improve attitudes toward learning and reduces teaching time. This teaching-and-learning tool offers true interactivity for the students and experience-based learning.

\section{CONCLUSIONS}

In this paper, the application of gaming-based technology to the community health nursing curriculum was introduced. The strategy based interactive community simulation environment addresses the learning needs of millennial students while bridging the large gap between the use of innovation and technology in learning and community health nursing curriculums. Future work includes the development of various learning modules to complement the existing ones. New modules that will be developed include the following:

Surveillance/Epidemiology Students will examine the control and management of a variety of communicable disease outbreaks using sound principles of epidemiology.

Emergency Preparedness Students will be able to practice and develop the skills and critical thinking necessary to plan and act during an emergency situation.

Research/Evaluation Students will examine and actively evaluate a variety of interventions/programs based on health issues/problems identified and strategies implemented in previous modules.

Future work also includes greater, more extensive evaluation that includes user testing. In particular, the simulation will be incorporated into an existing undergraduate community health nursing curriculum at the University of Ontario Institute of Technology. Here, its applicability and effectiveness will be evaluated and in-course corrections and iterations will be made accordingly. Finally, evaluation will also examine the developed application's effectiveness in meeting millennial students' learning needs, and in increasing the skills, knowledge and competence required to function as a community health nurse, as well as feelings of self-efficacy.

\section{REFERENCES}

[1] J. P. Gee. What Video Games Have to Teach Us About Learning and Literacy. Palgrave MacMillan, New York, NY. USA, 2003.

[2] D. A. Lieberman. Interactive video games for health promotion: Effects on knowledge, self-efficacy, social support and health. In R. L. Gold and T. Manning, editors, Health Promotion and Interactive Technology, pages 103-120. Lawrence Erlbaum Associates, Norwell, NJ. USA, 1997.

[3] K. Mangold. Educating a new generation: Teaching baby boomer faculty about millennial students. Nurse Educator, 32(1):21-23, 2007.

[4] Public Health Agency of Canada. Core competencies for publc health (draft 2). Technical report, Ottawa, Ontario, Canada, October 52006.

[5] D. Michael and S. Chen. Serious Games: Games That Educate, Train and Inform. Thomson Course Technology, Boston, MA. USA, 2006.

[6] A. Mitchell and Savill-Smith. The use of computer and video games for learning: A review of the literature. www.LSDA.org.uk, 2004.

[7] M. Prensky. Computer games and learning: Digital game-based learning. In J. Raessens and J. Goldstein, editors, Handbook of Computer Game Studies, pages 97-122. MIT Press, Cambridge, MA. USA, 2005.

[8] B. D. Ruben. Simulations, games, and experience-based learning: The quest for a new paradigm for teaching and learning. Health Education Research, Theory and Practice, 30(4):498-505, 1999.

[9] B. Sibbald. 2020 vision of nursing. Canadian Nurse, 91(3):33-36, 2005.

[10] A. J. Stapleton. Serious games: Serious opportunities. In Proceedings of the 2004 Australian Game Developers' Conference, pages 1-6, Melbourne, Australia, 2004

[11] P. A. Stout, J. Villegas, and H. Kim. Enhancing learning through use of interactive tools on health-related websites. Health Education Research, Theory and Practice, 16(1):721-733, 2003.

[12] T. Susi, M. Johannesson, and P. Backlund. Serious games an overview. Technical Report HS-IKI-TR-07-001, School of Humanities and Informatics, University of Skovde, Sweden, February 2007.

[13] R. Thomas, J. Cahill, and L. Santilli. Using an interactive computer game to increase skill and self-efficacy regarding safer sex negotiation: Field test results. Health Education and Behavior, 24(1):71-86, 1997.

[14] M. Villeneuve and J. MacDonald. Toward 2020: Visions for nursing. Technical Report ISBN 1-55119-818-5, Canadian Nurses Association, Ottawa, Ontario, Canada, 2006. 